\title{
Participatory surface algal bloom monitoring in Finland in 2011-2013
}

\author{
Ville Kotovirta ${ }^{1 *}$, Timo Toivanen ${ }^{1}$, Marko Järvinen ${ }^{2}$, Matti Lindholm³ ${ }^{3}$ and Kari Kallio ${ }^{3}$
}

\begin{abstract}
Background: Algal mass occurrences are one of the most distinguishing effects of eutrophication in lakes and the coastal waters of the Baltic Sea. Algal bloom occurrence in water bodies varies greatly in terms of both space and time, even during short periods, which makes reliable monitoring of blooms difficult. In this paper, we explore the possibilities to extend the sensor network both spatially and temporally by applying participatory sensing to surface algal bloom monitoring in Finnish lakes and the coastal areas of the Baltic Sea.
\end{abstract}

Results: Two participatory sensing systems were used to collect visual algae observations by citizens: the mobile phone application Levävahti (Algae Watch) and the collaborative web service Järviwiki (Lake wiki), during the summers of 2011-2013. Citizen observations were compared with the visual observations performed by trained expert observers, and mean correlations between citizen and expert observations were calculated using the bootstrapping method: $0.72,95 \%$ confidence interval $(\mathrm{Cl})[0.530 .86] ; 0.65,95 \% \mathrm{Cl}[0.350 .86]$; and $0.56,95 \% \mathrm{Cl}$ [0.29 0.76] for the years 2011, 2012 and 2013.

Conclusions: Surface algal bloom monitoring is needed to obtain data on algal bloom frequency and intensity, in particular in lakes where the use of satellite remote sensing has limitations and/or phytoplankton monitoring is infrequent or totally lacking. The correlations between expert and citizen observations suggest that citizen observers can provide additional information to support algal bloom monitoring of inland and coastal waters.

Keywords: Algal bloom monitoring; Cyanobacteria; Lakes; the Baltic Sea; Mobile phone; Participatory sensing; Citizen science

\section{Background}

\section{Algal bloom monitoring}

Algal mass occurrences, in particular cyanobacterial surface blooms, are one of the most distinguishing effects of eutrophication in lakes and the coastal waters of the Baltic Sea (Solimini et al. 2006). It is therefore logical that the frequency and intensity of cyanobacterial blooms are used in the assessment of the ecological status of surface water bodies in Europe under the European Water Framework Directive (European Commission 2000; Carvalho et al. 2013). Algal bloom occurrence in water bodies varies greatly in terms of both space and time, even during short periods, which makes reliable monitoring of blooms difficult. Traditional manual monitoring with biweekly to monthly or longer sampling frequency easily leads to

\footnotetext{
*Correspondence: ville.kotovirta@vtt.fi

'VIT Technical Research Centre of Finland, P.O. Box 1000, FI-02044, VTT Espoo, Finland

Full list of author information is available at the end of the article
}

situations in which not all bloom events can be detected. Remote sensing of algal mass occurrences by satellites can provide high temporal and spatial resolution bloom information of sea areas (e.g. Reinart and Kutser 2006). Monitoring of small water bodies by satellite remote sensing requires images with a good spatial resolution $(<30 \mathrm{~m})$. At present, such images are not operationally available on a daily basis. One possible way to increase information on cyanobacterial surface bloom situations is to conduct visual observations of blooms by trained observers at fixed observation sites and periods, a method that has been used in Finland since 1998 to estimate average weekly surface bloom situations (Rapala et al. 2012). Although these results cannot at present be used as a bloom metric to assess ecological status, due to a lack of reference conditions and class boundary values, they can be used to support classification decisions by expert judgement (Aroviita et al. 2012). Due to the large number of lakes in Finland ( $>188000$ with a surface area of $>5$ acres), visual 
observations by trained observers are restricted to a rather limited set of lakes.

One possible way to increase both temporal and spatial coverage of surface bloom visual observations in a larger number of lakes and the coastal regions of the Baltic Sea is to include citizens as observers. This has already started in Finland, but the applicability of the observations made by citizens has not been verified before.

\section{Citizen science and participatory sensing}

Citizen contributions to environmental monitoring are increasing (Conrad and Hilchey 2011). This is part of a broader emerging field of citizen science in which citizens produce scientifically meaningful observations or analyses (Haklay 2012). Citizen science has been successfully applied to ecological research, e.g. for monitoring birds, insects and invasive plants (Dickinson et al. 2012), and citizens have been involved in environmental monitoring, to some extent, for over a hundred years (e.g. the Christmas Bird Watch, started by ornithologists of North America, has been ongoing since 1900, Haklay 2012).

Recent advances in information and communication technology (ICT) and increased awareness of the status of the environment, in particular global climate change, have activated people even more to participate in monitoring (Burke et al. 2006). Mobile devices with GPS receivers provide a useful platform for collecting data about the environment. Citizens can provide observations actively themselves (i.e. participatory sensing), enable their mobile devices to collect data automatically (i.e. opportunistic sensing, Lane et al. 2008) and analyse or discuss the data or the environmental conditions using proprietary software or social media tools such as Facebook, Google+ and Twitter.

Methods for participatory and opportunistic citizen sensing have been presented for various applications and in various forms. Eiman (2010) presented a method for mapping noise levels in a city area, while Paxton and Benford (2009) described a study in which $\mathrm{CO}_{2}$ level measurements were observed with a handheld device and combined with written observations and video clips. Mednis et al. (2011) developed a system for road irregularity detection using data from accelerometers of mobile phones.

Citizen sensing has been applied to hydrology, and, e.g., Olmanson et al. (2008) used citizen Secchi depth measurements as in-situ data source for satellite image calibration, Sunyoung et al. (2011) developed a mobile application (Creek Watch) for citizens to monitor waterways (amount of water, rate of flow and amount of litter), Lowry and Fienen (2013) presented a method for stream stage monitoring in which citizen passers-by make observation using fixed measuring devices, Toivanen et al. (2013) presented a method for observing Secchi depth and turbidity using an inexpensive measurement device and a mobile phone camera, and Leeuw and Boss (2014) developed the HydroColor app which estimates the concentration of total suspended matter and the backscattering coefficient from water reflectance measured by a mobile phone camera. The European Environment Agency published the Marine LitterWatch mobile phonebased app (http://www.eea.europa.eu/themes/coast_sea/ marine-litterwatch) in 2013 to involve citizens in the monitoring of marine litter distribution and composition. The app was specifically developed for the needs of the EU's Marine Strategy Framework Directive.

Suggested architectures and platforms for more generic participatory sensing include G-Sense (Perez et al. 2010), PRISM (Platform for Remote Sensing using Smartphones) (Das et al. 2010), the personal environmental impact report PEIR (Mun et al. 2009) and the EnviObserver participatory sensing system (Kotovirta et al. 2012).

\section{Focus of this paper}

In this paper we discuss the results of applying participatory sensing to surface algal bloom monitoring in Finnish lakes and the coastal areas of the Baltic Sea during the summers of 2011, 2012 and 2013. The hypothesis is that voluntary citizen monitoring can extend the existing sensor and observation networks both spatially and temporally and provide useful information about cyanobacterial bloom coverage. We compared the citizen observations with weekly observations made by trained experts and found a clear correlation between the bloom intensity averages, supporting our hypothesis.

\section{Results}

\section{Number of observations}

A total of 4572 trained expert observations and 872 volunteer citizen observations, of which 269 were made using the mobile phone application, were received during the weeks 24 to 38 in the summer of 2011. In the summer of 2012, 4427 expert observations and 319 citizen observations (156 mobile) were received, and in the summer of 2013, 4150 expert observations and 465 citizen observations (134 mobile) were performed (Table 1). Figure 1 presents a comparison of the locations of the expert observation sites with the citizen observations for the summer of 2011. To analyse the spatial distribution of the citizen and expert observations the numbers of observations were calculated for rectangles sized one degree (latitude) by two degrees (longitude) covering the whole dataset. The most observations were done in south and south-west Finland for the year 2011, and a similar pattern was also observed for the years 2012 and 2013.

The number of volunteer citizen observations was highest in the summer of 2011. This probably resulted 
Table 1 Yearly counts and correlations

\begin{tabular}{|c|c|c|c|c|c|c|c|c|c|c|c|}
\hline \multirow[b]{2}{*}{ Year } & \multirow[b]{2}{*}{ Area } & \multicolumn{3}{|l|}{ Count } & \multicolumn{2}{|c|}{ ‘No algae' } & \multirow[b]{2}{*}{$\begin{array}{l}\text { Correlation } \\
\text { of original } \\
\text { datasets }\end{array}$} & \multirow[b]{2}{*}{$\begin{array}{l}\text { Mean of } \\
\text { bootstrap } \\
\text { correlations }\end{array}$} & \multirow[b]{2}{*}{$95 \%$ confidence } & \multirow[b]{2}{*}{$\begin{array}{l}\text { Citizen } \\
\text { spatial } \\
\text { correlation }\end{array}$} & \multirow[b]{2}{*}{$\begin{array}{l}\text { Citizen } \\
\text { count } \\
\text { correlation }\end{array}$} \\
\hline & & Experts & Citizens & Mobile & Experts & Citizens & & & & & \\
\hline 2011 & Whole & 4572 & 872 & $31 \%$ & $80 \%$ & $60 \%$ & 0.82 & 0.72 & {$\left[\begin{array}{ll}0.53 & 0.86\end{array}\right]$} & -0.20 & -0.50 \\
\hline 2012 & Whole & 4427 & 319 & $49 \%$ & $86 \%$ & $52 \%$ & 0.88 & 0.65 & {$\left[\begin{array}{lll}0.35 & 0.86\end{array}\right]$} & -0.27 & -0.59 \\
\hline 2013 & Whole & 4150 & 465 & $29 \%$ & $83 \%$ & $42 \%$ & 0.69 & 0.56 & {$\left[\begin{array}{lll}0.29 & 0.76\end{array}\right]$} & -0.32 & -0.68 \\
\hline 2011 & Area1 & 283 & 217 & $20 \%$ & $76 \%$ & $79 \%$ & 0.64 & 0.47 & {$\left[\begin{array}{ll}0.13 & 0.79\end{array}\right]$} & -0.24 & 0.16 \\
\hline 2011 & Area2 & 1257 & 433 & $35 \%$ & $73 \%$ & $61 \%$ & 0.84 & 0.71 & {$\left[\begin{array}{lll}0.49 & 0.88\end{array}\right]$} & -0.04 & -0.03 \\
\hline 2012 & Area2 & 1242 & 196 & $45 \%$ & $78 \%$ & $54 \%$ & 0.55 & 0.40 & {$\left[\begin{array}{lll}0.05 & 0.71\end{array}\right]$} & 0.68 & -0.00 \\
\hline 2013 & Area2 & 1108 & 182 & $35 \%$ & $73 \%$ & $54 \%$ & 0.80 & 0.57 & {$\left[\begin{array}{ll}0.21 & 0.82\end{array}\right]$} & -0.45 & -0.47 \\
\hline
\end{tabular}

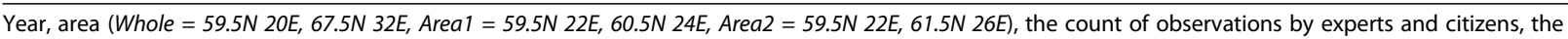
percentage of citizen mobile observations, percentages of 'no algae detected' observations, the correlation of expert and citizen weekly averages using the original datasets, mean of correlations calculated using bootstrapping method, $95 \%$ confidence interval of the bootstrap correlations, the correlation of weekly citizen observations' variation and the weekly spatial distribution (citizen spatial correlation), and the correlation of the weekly citizen observations' variation and the weekly count of observations (citizen count correlation).

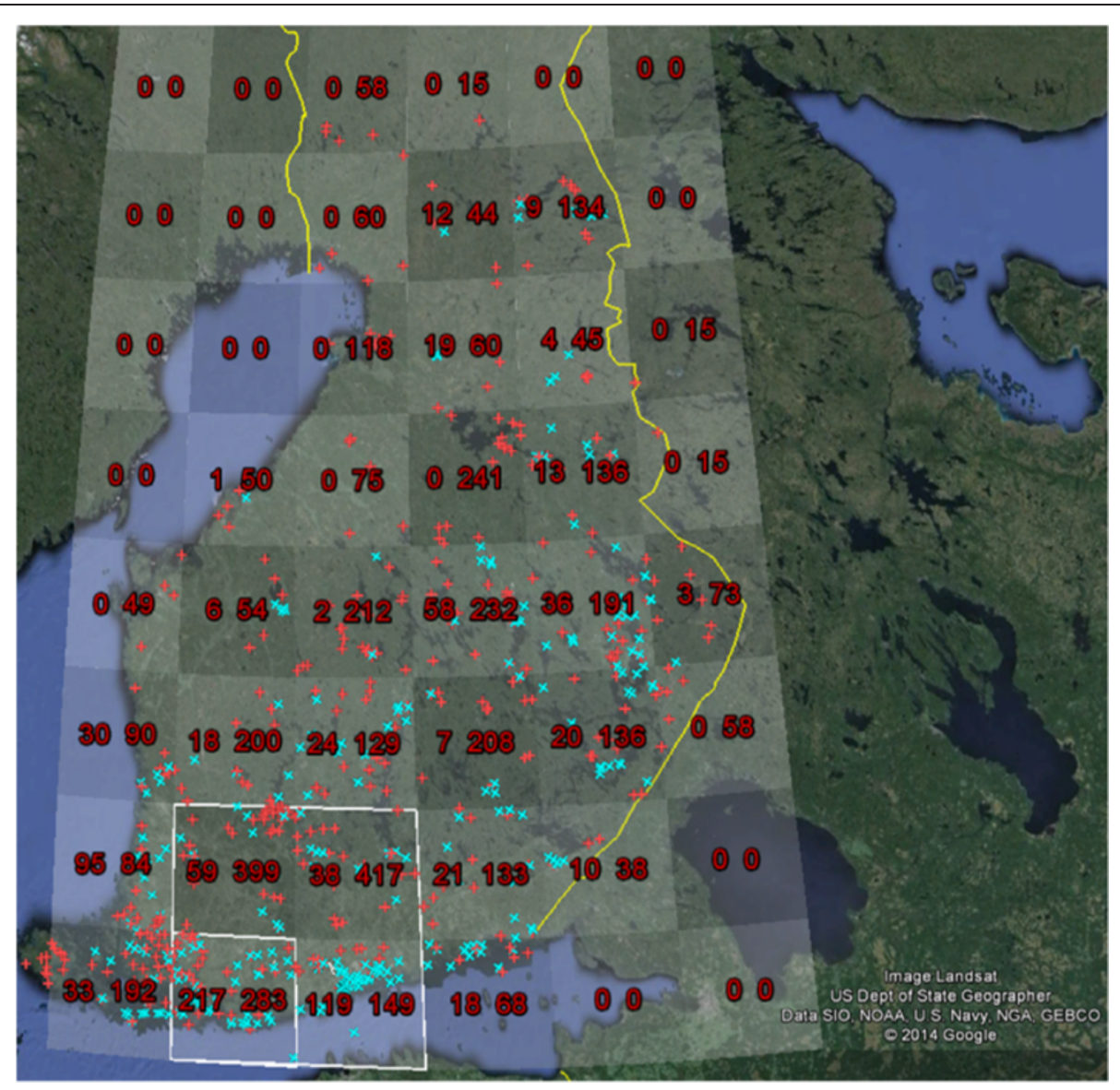

Figure 1 Comparison of the geographical locations of the citizen and expert observations in the summer of 2011. The blue xs indicate the locations of the citizen observations and the red plus signs (' + ') indicate the pre-determined locations of the expert observation sites. The numbers of citizen and expert observations (in this order) are presented for each grey rectangle (dimension of one degree latitude and two degrees longitude) which together cover the whole dataset (approx. 59.5N 20E, 67.5N 32E). The white rectangles indicate the smaller areas used in the analysis (Area1 $=59.5 \mathrm{~N} 22 \mathrm{E}, 60.5 \mathrm{~N} 24 \mathrm{E}$ and Area2 $=59.5 \mathrm{~N} 22 \mathrm{E}, 61.5 \mathrm{~N} 26 \mathrm{E}$ ). 
from a worse surface algal bloom situation (i.e. more surface blooms) in 2011 than in subsequent years, which probably made citizens more eager to make observations. The overall algal bloom intensity was estimated by taking the average value of all the expert observations, which was 0.21 for the summer of 2011, 0.15 for the summer of 2012 and 0.19 for the summer of 2013. These correlate with the total number of citizen observations (831, 303 and 443).

\section{Weekly averages}

The weekly averages of both citizen and expert observations and the 95\% confidence intervals calculated using the bootstrapping method are presented in Figures 2, 3 and 4 for the years 2011, 2012 and 2013, respectively. The best accuracy for citizen observation averages was achieved for the year 2011 and the weakest for 2012 . This may be again explained by the overall algae situation and the amount of citizen observations collected yearly. The percentage of citizen mobile observations and the percentages of 'no algae detected' observations are given in Table 1 for each year. The percentage of citizen mobile observations was around $30 \%$ for the years 2011 and 2013, and around 50\% for the year 2012, although the total number of citizen observations was the lowest for 2012. The citizen averages are biased towards higher bloom intensity values than the averages of the expert observations, which can be seen in Figures 2, 3 and 4 . One possible explanation, but not necessarily the only one, is revealed by comparing the percentages of 'no algae detected' (i.e. observation value ' 0 ') by citizen and expert observers. The portion of 'no algae' observations is lower for citizens than for experts, and therefore the averages of citizen observations are biased

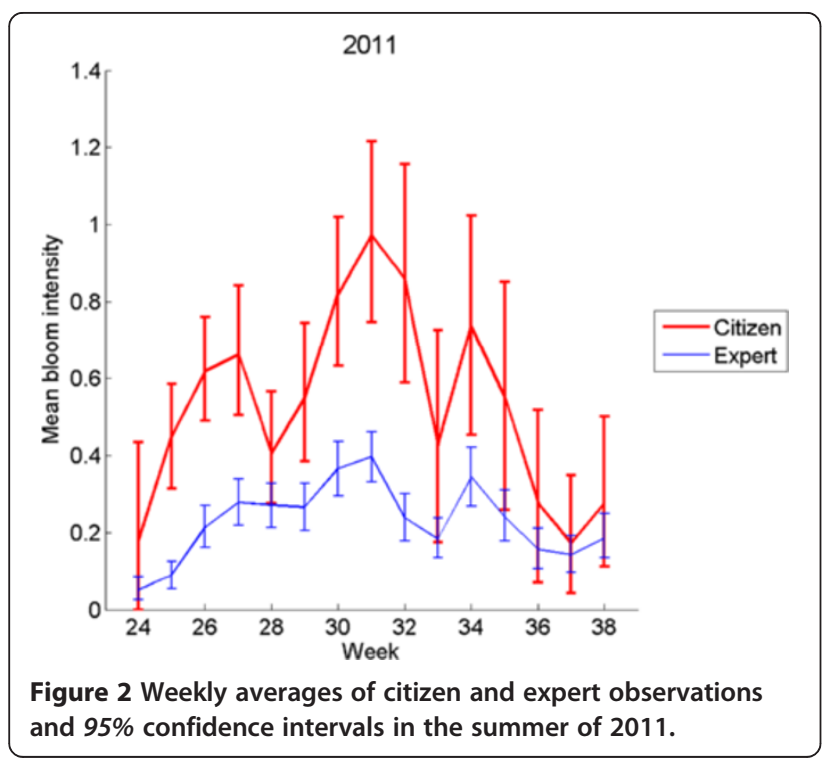

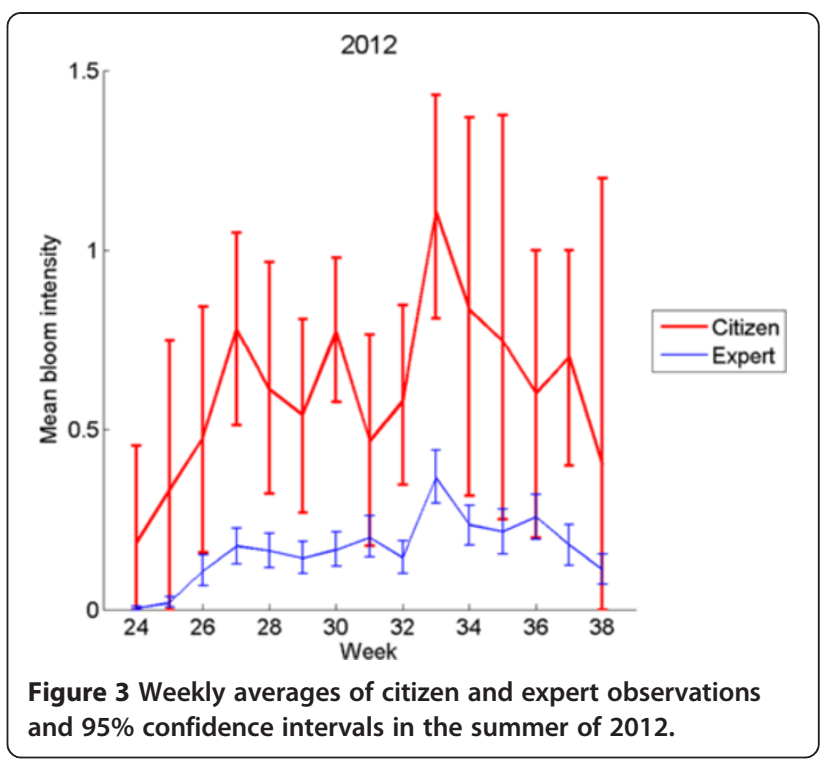

towards higher values (see also discussion about data quality).

\section{Correlations}

The correlations of expert and citizen weekly averages and their 95\% confidence intervals for each year are given in Table 1. We show both the correlations calculated from the original datasets and the mean of correlations calculated using the bootstrapping method. The correlation histograms are given in Figures 5, 6 and 7 and they represent graphically the correlation distributions. It can be seen that the distributions are left-tailed or left-skewed, and the corresponding skewness values are $-0.45,-0.80$, and -0.56 for the years 2011,2012 and 2013. It appeared that the correlation calculated from the original datasets for the year 2012 was above the

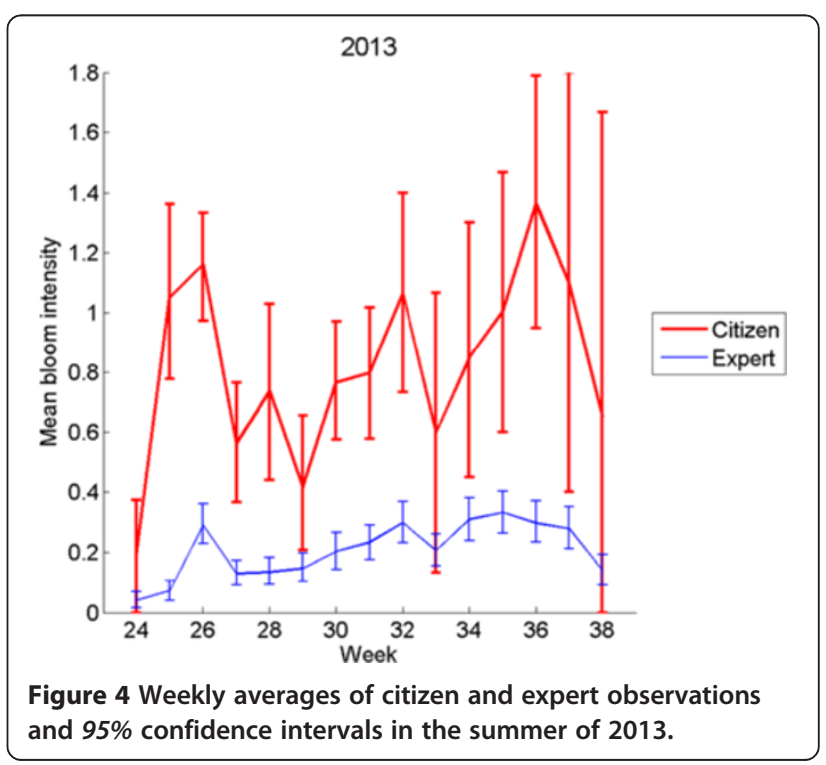




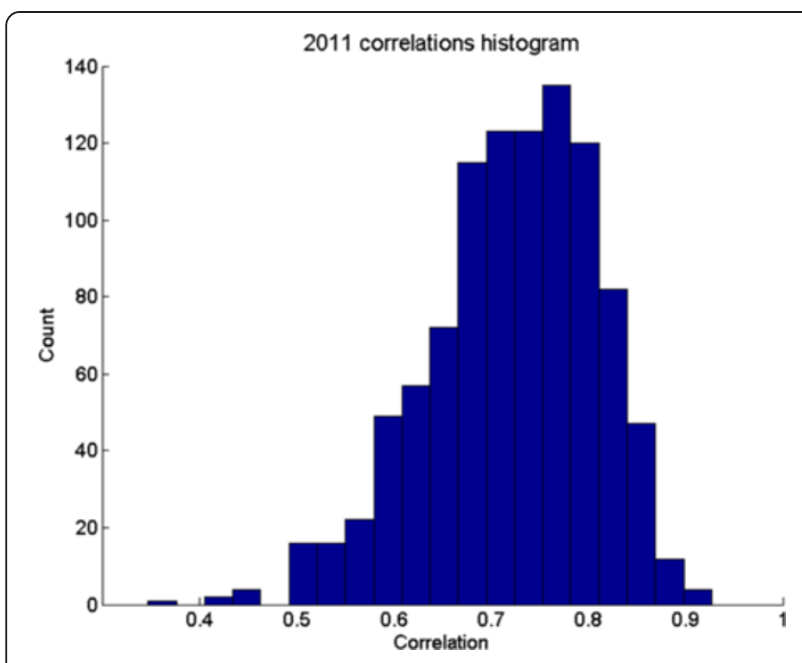

Figure 5 Histogram of the correlations of the citizen and expert weekly averages in the summer of 2011.

calculated 95\% confidence interval, which was anticipated to be due to pure chance, but it also shows how the original correlation would not probably be a reliable estimator of the true correlation. The correlation between the weekly citizen $95 \%$ confidence interval width, i.e. the variation of the citizen weekly averages, and the citizen observations' spatial distribution, and the correlation between the variation of the citizen weekly averages and the number of citizen observations are also given in Table 1. The correlations indicate that the spatial distribution of the citizen observations does not clearly explain the variation of weekly averages, but the negative correlations of the number of citizen observations and the variation (for the whole geographic area) indicate that the more observations there are for one

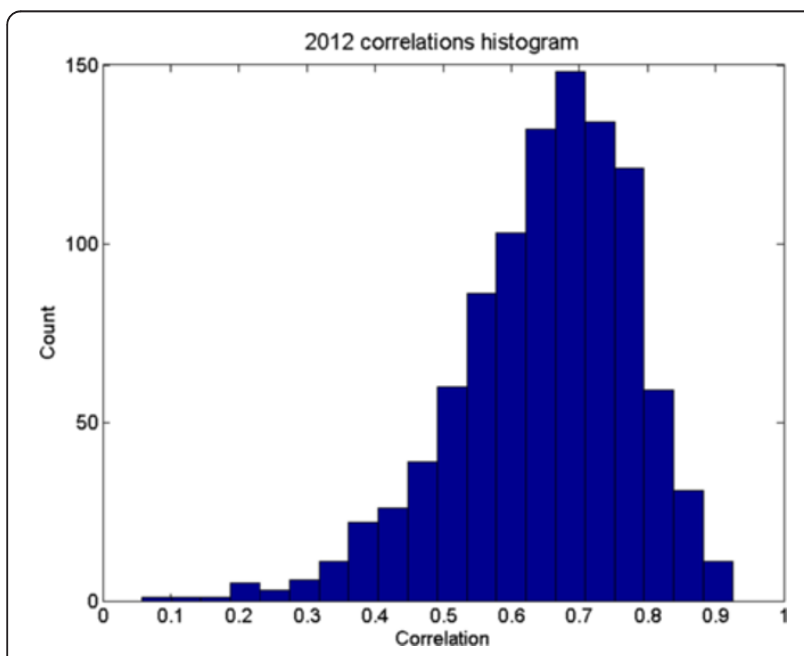

Figure 6 Histogram of the correlations of the citizen and expert weekly averages in the summer of 2012.

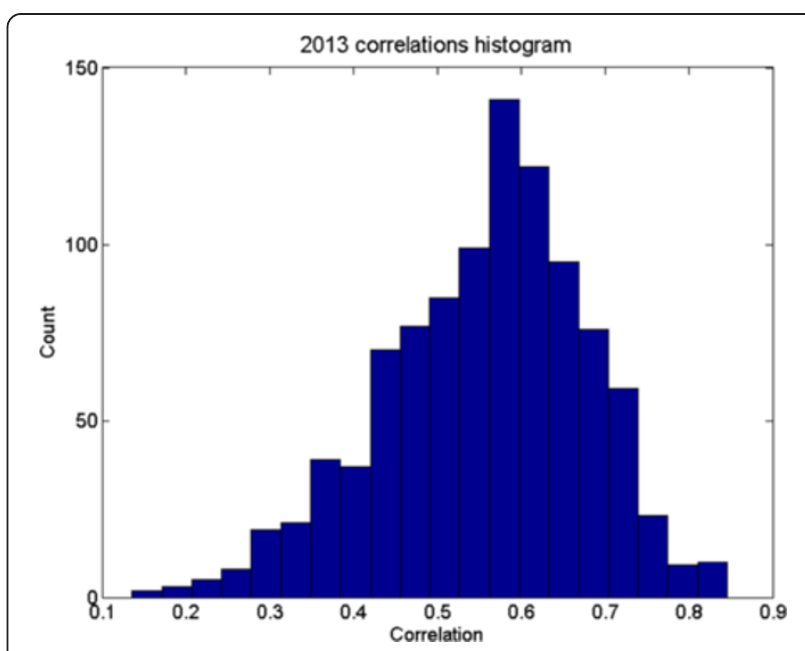

Figure 7 Histogram of the correlations of the citizen and expert weekly averages in the summer of 2013.

week the narrower is the confidence interval of the average, which shows consistency in the data.

\section{Discussion}

\section{Citizen activity}

Every year during the test period, the citizen activity tends to decrease towards the end of the summer, although the bloom events have not yet decreased markedly. This drop in observation activity may be explained by the summer holiday season in Finland, which commonly starts in mid-summer and lasts until the beginning of August, i.e. weeks 25 to 31. There are more potential citizen observers near waters (e.g. through boating, water sports, active use of summer cottages) in the middle of the holiday season.

In addition to the surface bloom situation and holiday season, other factors are likely to influence the observer activity. We published invitations to participate in the pilot study in local and national news services and at water-related events and exhibitions at the beginning of the summer algal growth season in Finland, but we did not follow up how well the message was received by potential users. We did not require any registration for the mobile part of the system, which makes the adoption of the system easier, but, at the same time, it makes the analysis in detail of the user activity and motivation of making observations more difficult.

Different frameworks have been suggested to motivate citizen observers. Reddy et al. (2010a) presented a recruitment framework for identifying potential participants for data collections, and Juong-Sik and Hoh (2010) discussed an incentive mechanism for stimulating participatory sensing applications. Micro-payments as an incentive mechanism are explored by Reddy et al. (2010b). 
We used a simple motivation mechanism in which users received notifications about the algae situation and reminders to contribute to observations. In the future, more efforts are needed to recruit suitable observers and to motivate them to continue making observations. Sunyoung et al. (2011) suggest that creating a successful citizen sensing application requires the application to be designed together with various stakeholders and ensuring that the gathered data can be put to use. Currently, as part of the MARMONI EU Life+ project (http://marmoni.balticseaportal. net/wp/), representatives of non-governmental organizations and school teachers are trained to make algae (cyanobacterial bloom and bladderwrack occurrence) and Secchi depth observations. The idea is that the representatives will act as trainers in their organizations and schools.

In general, the citizens are motivated to participate in environmental science projects (Roy et al. 2012). However, one challenge of harnessing citizen observers is to find an economically sustainable solution that motivates not just the citizens and researchers but also the system developers to innovate, update and maintain state-ofthe-art, easy-to-use tools for making observations. Citizen sensing activities and campaigns can be funded in the context of research projects, but to fully empower citizens as observers of various environmental parameters also requires new commercial innovations.

\section{Data quality}

The quality of the collected information is an important concern of citizen sensing (Haklay et al. 2010, Comber et al. 2013). In many cases, the quality varies, it is not documented at all, it fails to follow scientific principles of sampling design, and its coverage is incomplete (Goodchild and Li 2012).

When looking at the data and graphs of this study, we note that the citizen observation averages are biased towards higher bloom intensity values than the expert observation averages. This can be explained by noting that the citizens made fewer 'no algae detected' observations than the experts. Trained observers are instructed to make observations whether there are algae or not, but citizens make observations whenever they find it useful. Citizens probably make observations more often when algae are visible and tend to omit 'no algae' reports.

When the observations are based on human senses, the measurements are not of uniform quality but vary according to individual capabilities. In this study the citizen observers had also the possibility to submit photos along with their classification of algal blooms. The quality of these photos varies depending on the mobile phone model, the camera resolution, the distance, angle of view and degree of possible surface reflection, and therefore automatic classification of algal blooms is not feasible. However, the photos can be used visually as an additional method to verify the citizen observations.

As in any data gathering task relying on volunteer user contributions, there is a risk of faulty input by human errors or even service misuse. The risk of misuse may be even higher when no registration to the service is required and the abusers cannot be tracked. It is important to determine the quality of user observations, especially when using the data for evaluating and validating predictive models or as ground-truth data for reference. During the performed pilot trials, no service misuse was detected, and no actions to remedy that kind of activity were necessary. Obvious test uses of the system were detected manually, but in the future some automatic identification of faulty or accidental observations should be implemented to improve the data quality. For example, Alabri and Hunter (2010) describe a framework combining data quality control and trust metrics to enhance the reliability of citizen science data, and Kuan et al. (2010) as well as Yang et al. (2011) propose reputation management systems to evaluate the trustworthiness of gathered data by co-observers and data end-users.

Data privacy is one concern that must be considered, and it is discussed in several studies, e.g. Christin et al. (2011) conducted a survey on privacy in mobile participatory sensing applications and showed that almost all applications capture location and time information. Methods for protecting privacy have been presented, e.g. by Kazemi and Shahabi (2011). In our case the mobile citizen observers were anonymous so the privacy was not the primary concern, however, with the missing contact details we could not ask for feedback about the mobile system. Even though the names of the observers were not public (or not even available), individual identities could be inferred from the location information, e.g. if a summer cottage is used as a regular observation station. If data privacy becomes an issue later on the exact location could be hidden in the published data and stored unaltered for research purposes.

Our study was based on realistic data collected from experts making observations regularly in stationary locations and citizens making observations at more or less sporadic locations and times. The dataset did not enable very accurate comparison of expert and citizen observations in terms of space and time. We compared average values of large geographic area, which introduced errors in the data and therefore uncertainties in the results, as the algal bloom may develop differently in different parts of the averaged area. To study the quality of citizen observations in more detail, a special campaign could be organised to ensure that citizens and experts observe the same algae situation in the same region at the same time. 


\section{Usefulness of the data collected}

Based on our analysis, the systematic positive correlations between the expert and citizen algae observations in consequent years suggest that citizen observers can extend the current observation network spatially and temporally and provide additional information that supports the monitoring of the algal bloom situation. Already now the visual algal bloom observations by experts are used as supporting information for the Water Framework Directive (WFD) ecological classification of surface waters. All lakes in Finland cannot be monitored by authorities with available resources, thus citizens can provide additional information from areas that are not currently monitored and additional sampling of water quality can be carried out in areas where citizens have reported algal blooms.

The reliability and usefulness of citizen observations for monitoring terrestrial and marine environments have been analysed in several studies. Obrecht et al. (1998) conclude that citizen Secchi depth measurements are nearly identical with the measurements made by professionals. Delaney et al. (2008) identified obstacles in citizen monitoring and concluded that, with proper training, citizens can provide reliable aid in collecting knowledge about both native and invasive crabs. A study by Gallo and Waitt (2011) concludes that citizen scientists are able to detect and report invasive plants in their local areas, and the data can be used by professional scientists. D'Hondt et al. (2012) created noise maps based on citizen observations and concluded that they are comparable with official simulation-based noise maps. Lottig et al. (2014) analysed over 140000 Secchi observations from 3251 lakes in the USA and demonstrated that citizen science can provide the critical monitoring data needed to improve spatial and temporal scales.

\section{Conclusions}

Surface algal bloom monitoring is needed to obtain data on algal bloom frequency and intensity, in particular in lakes where the use of satellite remote sensing has limitations and/or phytoplankton monitoring is infrequent or totally lacking. In this paper we present how citizens can also take part in the algal bloom monitoring in Finland and thus accumulate additional information on bloom occurrences. Observations by untrained citizen observers were collected in the summers of 2011, 2012 and 2013 and compared with the trained expert observations. Two systems for citizen sensing were developed and applied in the study: a mobile phone application called Levävahti (Algae Watch) and a collaborative web service about Finnish lakes called Järviwiki (Lake wiki). A clear correlation between the expert and citizen observations was found in the analysis, which suggests that citizen observers can provide additional information for algae monitoring.

Europe is facing increasing monitoring requirements to meet obligations under, for example, the Water Framework Directive and the UN Convention on Biological Diversity (CBD). This opens up opportunities to develop and test new innovations for citizen science and community-based environmental monitoring. These innovations should not only provide new ways of gathering data but also engage and encourage the community in sustainable management of the environment.

\section{Methods}

\section{Visual observations of algal bloom situation}

In the visual algal bloom monitoring of Finnish waters, cyanobacteria bloom intensity is evaluated both by expert and citizen observers using four classes: $0=$ not detected, 1 = detected, $2=$ high amount and $3=$ very high amount (Rapala et al. 2012). Experts observe from June to September in the fixed shore observation sites, and citizens make additional observations for all water bodies at any time of year as frequently as they wish. The visual surface bloom observations focus on cyanobacteria (blue-green algae), as many bloom-forming cyanobacteria can form dense surface scums that can be toxic to humans as well as to other biota:

0: Not detected. No algae on the water surface or on the shore line. The Secchi depth visibility is normal.

1: Detected. Greenish flakes (cyanobacteria colonies) detected in the water or when taken into a transparent container, or narrow stripes on the shore. The Secchi depth is reduced by algae.

2: High amount. The water is clearly coloured by algae, small surface scums or cyanobacterial mass on the beach are detected.

3: Very high amount. Wide and heavy surface scums or thick aggregates of cyanobacteria are detected on the shore.

\section{Trained expert observations}

National surface algal bloom monitoring in Finland has been carried out since 1998. It is coordinated by the Finnish Environment Institute (SYKE) and carried out in co-operation with local environmental authorities, municipalities and private trained persons (Rapala et al. 2012). The aim of monitoring is to provide an up-todate overview of the cyanobacterial situation and information about the spatial and temporal variation during the summer.

The visual observations are made weekly by expert observers, i.e. authorities and trained volunteers, in approximately 320 pre-determined locations in Finland, of which approximately 260 represent lakes and 
approximately 60 coastal areas of the Baltic Sea. Observation sites have been selected to represent various types of waters with differing trophy, water colour (humic content), size and geographical location. Many observation sites are located near public beaches or cities. Many expert observers represent regional environment authorities from municipalities who are responsible for the monitoring of the status of recreational or drinking waters, incl. beaches, and who have been trained to detect cyanobacteria blooms by the phytoplankton and monitoring experts of the Centres of Economic Development, Transport and Environment or the Finnish Environment Institute (SYKE)

In this study, we concentrate on visual observations, as these can be compared with the citizen observations. However, other means are also used in algal monitoring, e.g. for the Finnish coastal areas of the Baltic Sea the information is obtained from satellite imagery, commercial ships with ship-of-opportunity devices and the Border Guard. In addition, if the amount of algae is visually estimated to be high or very high a sample is taken for the qualitative analysis of the bloom taxa using microscopy.

\section{Citizen observations}

In addition to observations by trained experts during the weekly national bloom situation monitoring, visual observations by untrained citizen observers were collected in 2011-2013. The architecture of the citizen observation system is depicted in Figure 8. Two applications for citizen sensing were developed and applied in the study to receive both mobile observations from ad-hoc locations and observations from stationary observation sites defined by citizens: the mobile phone application called Levävahti (Algae Watch) and the web-based lake information system called Järviwiki (Lake wiki, http://www.jarviwiki.fi/wiki/J\% C3\%A4rviwiki:About, Rapala et al. 2012). Citizens evaluated occurrences of algae with the same scale as trained observers irrespective of the observation application. The different algae classes and their criteria were described with example photographs in the applications' help pages to provide a tutorial about algae observation.

The Levävahti application (Algae Watch) was implemented on a participatory sensing platform called EnviObserver (Kotovirta et al. 2012) and was made available for Nokia (Java ME) and Android-based mobile phones in the

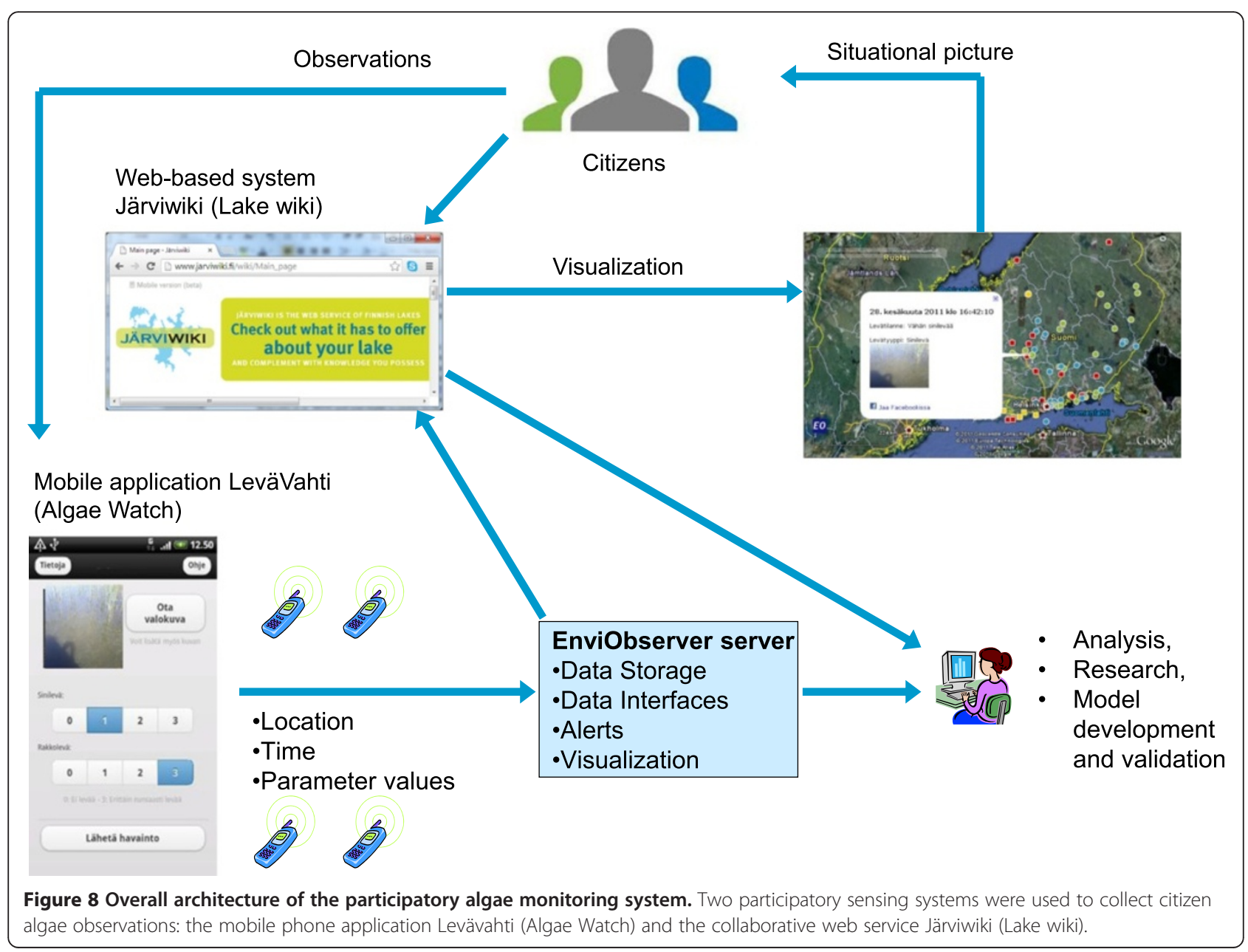


summer of 2011; for Nokia (Java ME), Android and iPhone phones in 2012 and 2013; and for Windows phones in 2013. The on-line observations were stored together with a GPS location, time and voluntary image taken by the user.

Järviwiki (Lake wiki) is a collaborative web service for sharing information about lakes in Finland, raising awareness and promoting protection of waters. The users of Järviwiki can write about or discuss a lake and set up their own observation sites and report on water parameters such as algal blooms, surface water temperature and ice cover. The visualizations of observations received from the Levävahti application and the observation sites in Järviwiki were implemented in the Järviwiki web service.

Citizen observers for the study were recruited by publishing invitations in local and national news services and water-related events and exhibitions at the beginning of the summer season in Finland. Cyanobacterial blooms are typically observed in Finnish waters from late June until the end of August. The mobile phone application was open to everyone without registration, requiring only downloading of the software. The Järviwiki web service was also open to everyone, but registration was needed to set up an observation site.

\section{Comparison}

To evaluate the usefulness of citizen observations, they were compared with the visual observations by experts. Due to the nature of this observation campaign, the locations and timing of the mobile phone citizen observations were quite sporadic, compared with the regular weekly observations by trained observers in pre-determined locations. The differences in location and timing did not enable direct comparisons between individual observations. Instead, we used averaging of both space and time and compared the averaged values. We calculated weekly averages for the whole geographic area of the dataset in Finland and for two smaller geographical areas (see Figure 1) to study the geographical variability of the observations. The sizes of the smaller areas were selected heuristically so that there were enough expert and citizen observations to calculate weekly averages. The smallest area was used only for the year 2011 dataset which contained enough observations for the analysis. The time range was restricted to weeks 24 to 38 (approx. early June to mid-Sept) in order to have enough citizen observations for weekly averaging. The algal blooming occurs during the summer months in Finland and the citizens appeared to be more active observers during the summer time.
We calculated the correlations between the weekly averages of citizen and expert observations for each year. In order to estimate the accuracy of the correlations we used the bootstrapping method, in which the observed data are used as an approximating distribution of the real distribution. We resampled random samples from each week's dataset and constructed a sampled observation dataset for each week that was equal in size to the original dataset. We then calculated new sampled averages for each week, and used those in calculating the correlations between citizen and expert observations. We repeated the process 1000 times and got distributions for weekly averages and also for the correlations of the weekly averages, and from the distributions we calculated the confidence intervals both for the weekly averages and the correlations of averages.

To study the variation of weekly averages of citizen observations we used the width of the $95 \%$ confidence interval as a measure of variation and calculated its correlation with the spatial distribution of citizen observations. The spatial distance between observations might (partly) explain the variation, as the algae situation may progress differently in different latitudes, or even in different lakes in the same latitude. The spatial distribution was calculated as a mean distance of the observations from their geographical centre point. We also calculated the correlation of the variation with the number of citizen observations.

\section{Competing interests}

The authors declare that they have no competing interests.

\section{Authors' contributions}

VK designed and conducted the research, analysed the results, drafted and polished the manuscript; VK and TT designed the EnviObserver and Levävahti system architectures and participated in the mobile application design; TT participated in the implementation of the mobile phone application and contributed to the manuscript; ML designed and implemented the Järviwiki web service, MJ coordinated the national algal bloom monitoring at the Finnish Environment Institute and contributed to the manuscript; KK participated in the mobile phone application design and contributed to the manuscript. All authors read and approved the final manuscript.

\section{Acknowledgements}

The work has been conducted in the Measurement, Monitoring and Environmental Assessment research programme funded by Tekes, the Finnish Funding Agency for Technology and Innovation, in the Pathway project funded by the Academy of Finland, and in the EU Life+ funded project GisBloom (Life09 ENV/FI/000569). We want to thank Markku Huttunen and Renne Tergujeff from VIT for their participation in the design and development of the Levävahti (Algae Watch) mobile application; Olli Saarela from VTT for his advice on data analysis; Seppo Kaitala, Maria Kämäri, Jari Silander and Juha-Markku Leppänen from the Finnish Environment Institute for participating in the design of Levävahti and the recruitment of participants; and Ville Peltola and Asko Relas from IBM Finland for participating in the mobile application design and developing the first iPhone version of LeväVahti for the summer of 2011.

\section{Author details}

${ }^{1}$ VTT Technical Research Centre of Finland, P.O. Box 1000, FI-02044, VTT Espoo, Finland. ${ }^{2}$ Finnish Environment Institute (SYKE), SYKE Jyväskylä Office, 
Survontie 9A, 40500 Jyväskylä, Finland. ${ }^{3}$ Finnish Environment Institute (SYKE), P.O. Box 140, 00251 Helsinki, Finland.

Received: 20 July 2014 Accepted: 19 November 2014 Published online: 02 December 2014

\section{References}

Alabri A, Hunter J (2010) Enhancing the quality and trust of citizen science data. In: Proceedings of 2010 6th IEEE International Conference on e-Science, eScience 2010, Brisbane, Australia, 7-10 Dec 2010

Aroviita J, Hellsten S, Jyväsjärvi J, Järvenpää L, Järvinen M, Karjalainen S-M, Kauppila P, Keto A, Kuoppala M, Manni K, Mannio J, Mitikka S, Olin M, Perus J, Pilke A, Rask M, Riihimäki J, Ruuskanen A, Siimes K, Sutela T, Vehanen T, Vuori K-M (2012) Guidelines for the ecological and chemical status classification of surface waters for 2012-2013 - updated assessment criteria and their application. Environmental Administration Guidelines 7/2012, Finnish Environment Institute (SYKE)., p 144, URN:SBN 978-952-11-4114-0. ISBN 978-952-11-4114-0

Burke J, Estrin D, Hansen M, Parker A, Ramanathan N, Reddy S, Srivastava M B (2006) Participatory Sensing. In: Proceedings of the International Workshop on World-Sensor-Web (WSW'2006), ACM, Boulder, CO, USA, 31 Oct 2006

Carvalho L, Poikane S, Lyche Solheim A, Phillips G, Borics G, Catalan J, De Hoyos C, Drakare S, Dudley BJ, Järvinen M, Laplace-Treyture C, Maileht K, McDonald C, Mischke U, Moe J, Morabito G, Nõges P, Nöges T, Ott I, Pasztaleniec A, Skjelbred B, Thackeray SJ (2013) Strength and uncertainty of lake phytoplankton metrics for assessing eutrophication impacts in lakes. Hydrobiologia 704:127-140, doi:10.1007/s10750-012-1344-1

Christin D, Reinhardt A, Kanhere SS, Hollick M (2011) A survey on privacy in mobile participatory sensing applications. J Syst Softw 84(11):1928-1946

Comber A, See L, Fritz S, Van der Velde M, Perger C, Foody G (2013) Using control data to determine the reliability of volunteered geographic information about land cover. Int J Appl Earth Obs Geoinf 23:37-48, ISSN 0303-2434, Available online http://dx.doi.org/10.1016/j.jag.2012.11.002 Accessed 8 Oct 2014

Commission E (2000) Directive 2000/60/EC of the European Parliament and of the Council of 23 October 2000 establishing a framework for Community action in the field of water policy. Off J Eur Communities 327:1-72

Conrad C, Hilchey K (2011) A review of citizen science and community-based environmental monitoring: issues and opportunities. Environ Monit Assess 176:273-291, doi:10.1007/s10661-010-1582-5

D'Hondt E, Stevens M, Jacobs A (2013) Participatory noise mapping works! An evaluation of participatory sensing as an alternative to standard techniques for environmental monitoring. Pervasive Mob Comput 9(5):681-694, ISSN 1574-1192, 10.1016/j.pmcj.2012.09.002

Das T, Mohan P, Padmanabhan V, Ramjee R, Sharma A (2010) PRISM: Platform for Remote Sensing using Smartphones. In: Proceedings of the 8th International Conference on Mobile Systems, Applications, and Services (MobiSys '10). ACM, New York, NY, USA

Delaney DG, Sperling CD, Adams CS, Leung B (2008) Marine invasive species: validation of citizen science and implications for national monitoring networks. Biol Invasions 10:1, doi:10.1007/s10530-007-9114-0

Dickinson JL, Shirk J, Bonter D, Bonney R, Crain RL, Martin J, Phillips T, Purcell K (2012) The current state of citizen science as a tool for ecological research and public engagement. Front Ecol Environ 10(6):291-297

Eiman K (2010) NoiseSPY: a real-time mobile phone platform for urban noise monitoring and mapping. Mob Netw Appl 15(4):562-574

Gallo T, Waitt D (2011) Creating a successful citizen science model to detect and report invasive species. Bioscience 61(6):459-465, doi:10.1525/bio.2011.61.6.8

Goodchild MF, Li L (2012) Assuring the quality of volunteered geographic information. Spat Stat 1:110-120, ISSN 2211-6753, available online http://dx.doi.org/10.1016/j.spasta.2012.03.002 Accessed 8 Oct 2014

Haklay M (2012) Citizen Science and Volunteered Geographic Information Overview and Typology of Participation. In: Sui DZ, Elwood S, Goodchild MF (eds) Volunteered Geographic Information, Public Participation and Crowdsourced Production of Geographic Knowledge. Springer, Berlin

Haklay M, Basiouka S, Antoniou V, Ather A (2010) How many volunteers does it take to map an area well? The validity of Linus' Law to volunteered geographic information. Cartogr J 47(4):315-322, 10.1179/000870410X12911304958827

Juong-Sik L, Hoh B (2010) Dynamic pricing incentive for participatory sensing. Pervasive Mob Comput 6(6):693-708

Kazemi L, Shahabi C (2011) Towards Preserving Privacy in Participatory Sensing. In: 2011 IEEE International Conference on Pervasive Computing and
Communications Workshops (PerCom Workshops). IEEE Computer Society, Seattle, WA, United States

Kotovirta V, Toivanen T, Tergujeff R, Huttunen M (2012) Participatory Sensing in Environmental Monitoring - Experiences. In: Innovative Mobile and Internet Services in Ubiquitous Computing (IMIS), 2012 Sixth International Conference, Palermo, Italy 4-6 July 2012., pp 155-162, do::10.1109/IMIS.2012.70

Kuan LH, Salil SK, Wen H (2010) Are You Contributing Trustworthy Data?: the Case for a Reputation System in Participatory Sensing. In: Proceedings of the 13th ACM international conference on Modeling, analysis, and simulation of wireless and mobile systems (MSWIM '10). ACM, New York, NY, USA

Lane ND, Eisenman SB, Musolesi M, Miluzzo E, Campbell A (2008) Urban sensing systems: opportunistic or participatory? In: Proceedings of the 9th workshop on Mobile computing systems and applications, CA, USA, 25-26 Feb 2008

Leeuw T, Boss E (2014) Crowdsourcing water quality data using the iPhone camera. Poster presented at the 2014 Ocean Science Meeting, Honolulu, Hawaii, 22 Feb-3 March 2014. Available online http://www.eposters.net/pdfs/ crowdsourcing-water-quality-data-using-the-iphone-camera.pdf Accessed 18 July 2014

Lottig NR, Wagner T, Norton Henry E, Spence Cheruvelil K, Webster KE, Downing JA, Stow CA (2014) Long-term citizen-collected data reveal geographical patterns and temporal trends in lake water clarity. PLoS ONE 9(4):e95769, doi:10.1371/journal.pone.0095769

Lowry CS, Fienen MN (2013) CrowdHydrology: crowdsourcing hydrologic data and engaging citizen scientists. GroundWater 51(1):151-156

Mednis A, Strazdins G, Zviedris R, Kanonirs G (2011) Real time pothole detection using Android smartphones with accelerometers. In: Proceedings of the 7th IEEE International Conference on Distributed Computing in Sensor Systems and Workshops (DCOSS'11), Barcelona, Spain 27-29 June 2011, pp 1-6

Mun M, Reddy S, Shilton K, Yau N, Burke J, Estrin D, Hansen M, Howard E, West R, Boda P (2009) PEIR, the personal environmental impact report, as a platform for participatory sensing systems research. In: MobiSys '09 Proceedings of the 7th international conference on Mobile systems, applications, and services, Kraków, Poland, 22-25 June 2009

Obrecht DV, Milanick M, Perkins BD, Ready D, Jones JR (1998) Evaluation of data generated from lake samples collected by volunteers. Lake Reserv Manag 14:21-27, doi:10.1080/07438149809354106

Olmanson LG, Bauer ME, Brezonik PL (2008) A 20-year Landsat water clarity census of Minnesota's 10,000 lakes. Remote Sense Environ 112:4086-4097, doi:10.1016/j.rse.2007.12.013

Paxton M, Benford S (2009) Experiences of Participatory Sensing in the Wild. In: Proceedings of the 11th International Conference on Ubiquitous Computing (UbiComp '09). ACM, New York, NY, USA, pp 265-274

Perez A, Labrador M, Barbeau J (2010) G-sense: a scalable architecture for global sensing and monitoring. IEEE Netw 24(4):57-64

Rapala J, Kilponen J, Järvinen M, Lahti K (2012) Finland: Guidelines for Monitoring of Cyanobacteria and their Toxins. In: Chorus I (ed) Current Approaches to Cyanotoxin Risk Assessment, Risk Management and Regulations in Different Countries. Federal Environment Agency (Umweltbundesamt), Germany, pp 54-62, http://www.uba.de/uba-info-medien-e/4390.html. Accessed 18 July 2014

Reddy S, Estrin D, Srivastava M (2010a) Recruitment framework for participatory sensing data collections. In: Proceedings of the 8th International Conference on Pervasive Computing, Helsinki, Finland, pp 138-155

Reddy S, Estrin D, Hansen M, Srivastava M (2010b) Examining Micro-Payments for Participatory Sensing Data Collections. In: Proceedings of the 12th ACM International Conference on Ubiquitous Computing (Ubicomp '10). ACM, New York, NY, USA, pp 33-36

Reinart A, Kutser T (2006) Comparison of different satellite sensors in detecting cyanobacterial bloom events in the Baltic Sea. Remote Sens Environ 102:74-85

Roy HE, Pocock MJO, Preston CD, Roy DB, Savage J (2012) Understanding citizen science \& environmental monitoring. Final report on behalf of UK Environmental Observation Framework. NERC Centre for Ecology \& Hydrology and Natural History Museum. http://www.ceh.ac.uk/products/ publications/documents/citizensciencereview.pdf

Solimini AG, Cardoso AC, Heiskanen AS (eds) (2006) Indicators and methods for the ecological status assessment under the Water Framework Directive, Linkages between chemical and biological quality of surface waters. European Commission, Luxembourg

Sunyoung K, Robson C, Zimmerman T, Pierce J, Haber E (2011) Creek Watch: Pairing Usefulness and Usability for Successful Citizen Science. In: 
Proceedings of the 2011 Annual Conference on Human Factors in Computing Systems (CHI '11). ACM, New York, NY, USA, pp 2125-2134 Toivanen T, Koponen S, Kotovirta V, Molinier M, Chengyuan P (2013) Water quality analysis using an inexpensive device and a mobile phone. Environ Syst Res 2(9) doi:10.1186/2193-2697-2-9

Yang H, Zhang J, Roe P (2011) Using reputation management in participatory sensing for data classification. Procedia Comput Sci 5:190-197

doi:10.1186/s40068-014-0024-8

Cite this article as: Kotovirta et al.: Participatory surface algal bloom monitoring in Finland in 2011-2013. Environmental Systems Research 2014 3:24.

\section{Submit your manuscript to a SpringerOpen ${ }^{\circ}$} journal and benefit from:

- Convenient online submission

- Rigorous peer review

- Immediate publication on acceptance

- Open access: articles freely available online

- High visibility within the field

- Retaining the copyright to your article

Submit your next manuscript at $>$ springeropen.com 